\title{
Phenotypic and genotypic characterization of Salmonella spp. isolated from foods and clinical samples in Brazil
}

\author{
ANDREA L. MIRANDA ${ }^{1}$, SORAIA M. CORDEIRO ${ }^{2}$, JOICE N. REIS ${ }^{2}$, \\ LUCAS G. CARDOSO ${ }^{1}$ and ALAÍSE G. GUIMARÃES ${ }^{3}$ \\ 'Programa de Pós-Graduação em Ciência de Alimentos, Laboratório de Estudos em \\ Microbiologia de Alimentos/LEMA, Faculdade de Farmácia, Universidade Federal da Bahia, \\ Av. Adhemar de Barros, s/n, Campus de Ondina, 40170-115 Salvador, BA, Brazil \\ ${ }^{2}$ Departamento de Análises Clínicas e Toxicológicas, Laboratório de Microbiologia Clínica, Faculdade de Farmácia, \\ Universidade Federal da Bahia, Av. Adhemar de Barros, s/n, Campus de Ondina, 40170-115 Salvador, BA, Brazil \\ ${ }^{3}$ Departamento de Análises Bromatológicas, Laboratório de Estudos em Microbiologia de Alimentos/LEMA, Faculdade de \\ Farmácia, Universidade Federal da Bahia, Av. Adhemar de Barros, s/n, Campus de Ondina, 40170-115 Salvador, BA, Brazil
}

Manuscript received on July 13, 2016; accepted for publication on December 6, 2016

\begin{abstract}
Increasing antimicrobial resistance in Salmonella species has been a serious problem for public health worldwide. This study examines Salmonella spp. recovered from foods and clinical samples on serotype, antimicrobial resistance and PFGE genotypes. It identified 91 salmonellae, belonging to 31 different serotypes, from 36 isolates from food and 55 clinical samples. Salmonella Infantis (16.5\%) and Salmonella Enteritidis (13.7\%) are the most common among food isolates, whereas Salmonella Enteritidis (29.0\%) and Salmonella Typhimurium (16.0\%) mainly causes human salmonellosis. Antimicrobial susceptibility data showed that $63.0 \%$ of the isolates were fully susceptible to 12 antibiotics tested. Nalidixic acid showed high resistance rates, $32.7 \%$ and $25.0 \%$ of the clinical isolates and food, respectively. Three main PFGE types: A (Salmonella Enteritidis), B (Salmonella Infantis) and C (Salmonella Schwarzengrund) comprised isolates recovered from foods and clinical samples. Our results indicate that the clonal groups were both causing diseases and food contamination, emphasizing the need to maintain a system of surveillance for foodborne disease.
\end{abstract}

Key words: Salmonella, Salmonella Infantis, Salmonella Enteritidis, antimicrobial resistance.

\section{INTRODUCTION}

Salmonella is a leading cause of food-borne disease being an important health problem in industrialized and developing countries (Chu et al. 2009, AbbassiGhozzi et al. 2012, Yang et al. 2013). In recent years, serotypes of Salmonella isolated from foods

Correspondence to: Andrea Lobo Miranda

E-mail: andrealobomi@yahoo.com.br have shown an increase in antimicrobial resistance, particularly those of animal origin. Moreover, an increased incidence of human salmonellosis due to multidrug-resistant strains have been reported $(\mathrm{Lu}$ et al. 2011, Wang et al. 2013).

There has been increasing concern over the past 30 years about the worldwide emergence of multidrug-resistant phenotypes among Salmonella 
serovars, in particular Salmonella Typhimurium and, more recently, Salmonella Newport as well as several other serovars. The levels and extent of resistance vary in different regions and are influenced by antimicrobial use in humans and animals as well as geographical differences in the epidemiology of Salmonella (Weinberger and Keller 2005, Zhao et al. 2008).

Most individuals with gastroenteritis present no serious clinical conditions and do not need hospitalization, so it is difficult to isolate the causative agents and identify the sources of contamination, thus underestimating the number of cases of salmonellosis worldwide. In Brazil, during the period of 2001 to 2006 , a total of 3,749 cases of typhoid fever were reported with 30 deaths, the highest number recorded in the North and Northeast regions, especially in the states of Acre (741 cases), and Bahia (671 cases) (Brazilian Ministry of Health 2009, Souza et al. 2010).

However, sporadic studies and limited information on Salmonella food contamination and microbiological investigation in foodborne infections have not clarified uncertainties regard of the salmonellosis epidemiology in Brazil (Campioni et al. 2012). Therefore, the current study evaluates the prevalence of antimicrobial susceptibility and genotypes of Salmonella spp. isolated from food and human in the state of Bahia (Northeast region) from 1996 to 2012.

\section{MATERIALS AND METHODS}

\section{SAMPLES}

This study analyzed 91 isolates of Salmonella spp. from various cities in the State of Bahia Brazil, 36 isolated from food (meat, fish, chicken and pork, cheeses, salads, rice, ready-to-eat foods and desserts). Food Isolates came from the Laboratory for Food Microbiology Research, Federal University of Bahia and the Central Public Health Laboratory of Bahia (LACEN/BA). Merchants and local health surveillance officers sent food samples to the laboratories with suspected food infection outbreaks, isolating them for identification of Salmonella. Isolated from clinical specimens (55 isolates) were isolated from human feces $(n=43)$, cerebrospinal fluid - CSF $(\mathrm{n}=10)$, and blood $(\mathrm{n}=$ 2) of patients treated at four hospitals in the city of Salvador, Bahia. Invasive CSF samples were obtained from patients with meningitis and blood and stool samples were obtained from patients with gastroenteritis suspected. The information provided by hospitals or food laboratories were referring to the year of isolation, source (feces, blood, CSF or food) and city of origin.

\section{SEROLOGICAL IDENTIFICATION}

The isolates were serotyped by the slide agglutination method using antisera prepared at the National Reference Laboratory for Enterobacteria of the Oswaldo Cruz Foundation in Rio de Janeiro (Fundação Oswaldo Cruz - FIOCRUZ-RJ).

\section{ANTIMICROBIAL SUSCEPTIBILITY}

Antimicrobial susceptibility was assessed to ampicillin $10 \mu \mathrm{g}$ (AMP), cephalothin $30 \mu \mathrm{g}$ (CFL), cefotaxime $30 \mu \mathrm{g}(\mathrm{CTX})$, gentamicin $10 \mu \mathrm{g}$ (GEN), tetracycline $30 \mu \mathrm{g}$ (TET), chloramphenicol $30 \mu \mathrm{g}$ (CLO), trimethoprim/sulfamethoxazole 1.25/23.75 $\mu \mathrm{g}$ (TMS), ciprofloxacin $5 \mu \mathrm{g}$ (CIP), amoxicillin/ clavulanate 20/10 $\mu \mathrm{g}$ (AMC), nalidixic acid $30 \mu \mathrm{g}$ (NLX), levofloxacin $5 \mu \mathrm{g}$ (LEV) and ceftriaxone $30 \mu \mathrm{g}$ (CRO). The agar diffusion method according to Clinical and Laboratory Standards Institute guidelines (CLSI 2016). The study adopted strain Escherichia coli ATCC $^{\circledR} 25922$ as reference for quality control.

\section{PFGE TYPING AND ANALYSIS}

Chromosomal digests generated by $X b a \mathrm{I}$ were prepared and analysed as described previously (CDC 2010). Fragments were separated in $1.0 \%$ 
agarose gels using using CHEF-DRII apparatus (Bio-Rad Laboratories, Hercules, CA) with pulse times of 2.2 to $63.8 \mathrm{~s}$ for $20 \mathrm{~h}$ at $14^{\circ} \mathrm{C}$ and $6 \mathrm{~V} / \mathrm{cm}$ in TBE buffer. Restriction profiles were analysed using GelCompar II (Applied Maths, St. Martens, Belgium). To develop the dendrogram, the study used an unweighted pair-group with arithmetic mean (UPGMA) method and the Dice similarity coefficient, with a position tolerance coefficient of $1.5 \%$. Isolates with $\geq 90.0 \%$ relatedness were considered a cluster.

\section{RESULTS}

Out of the 91 samples investigated, it was possible to identify 20 serotypes (Table I) from a set of isolates from food, of which $16.5 \%$ (6 of the 36) corresponded to serotype Salmonella Infantis (Figure 1).
Among isolates obtained from clinical samples, this study identified 18 different serotypes. Salmonella Enteritidis was predominant with 29.1\% (Figure 1). Serotype diversity was lower among clinical isolates than in foods samples (Table II).

In regards to antimicrobial resistance, $63.0 \%(57 / 91)$ of the isolates were sensitive to all antibiotics tested and 37.0\% (34/91) resistant to at least one of the 12 antibiotics tested (Table III). High resistance rates were seen for nalidixic acid among the isolates, $32.7 \%$ and $25.0 \%$ of the clinical isolates and food, respectively. In addition, isolates from clinical samples were more resistant than isolates from food: resistance to tetracycline (25.5\% vs. $8.3 \%)$, ampicillin (21.8\% vs. $5.6 \%)$ and TMS (14.5\% vs. $8.3 \%)$. However, amoxicillin/ clavulanate, cephalothin, chloramphenicol, ceftriaxone, cefotaxime and gentamicin showed

TABLE I

Distribution of Salmonella spp. serotypes from food isolates $(\mathrm{N}=36)$.

\begin{tabular}{|c|c|c|c|c|}
\hline Serotypes & Food Source & $\mathbf{N}^{0}$ of Isolates & Total & $\%$ \\
\hline \multirow{6}{*}{ Salmonella Infantis } & Salami & 1 & \multirow{6}{*}{6} & \multirow{6}{*}{16.5} \\
\hline & Cooked rice & 1 & & \\
\hline & Pork & 1 & & \\
\hline & Cooked chicken & 1 & & \\
\hline & Raw chicken & 1 & & \\
\hline & Uncooked seasoned pork & 1 & & \\
\hline \multirow{5}{*}{ Salmonella Enteritidis } & Peanut pave & 1 & \multirow{5}{*}{5} & \multirow{5}{*}{13.7} \\
\hline & Chocolate bonbon & 1 & & \\
\hline & Chocolate pave & 1 & & \\
\hline & Homemade cake & 1 & & \\
\hline & Strawberry syrup & 1 & & \\
\hline \multirow{3}{*}{ Salmonella Senftenberg } & Uncooked pork pepperoni & 1 & \multirow{3}{*}{3} & \multirow{3}{*}{8.2} \\
\hline & Charru Mussel & 1 & & \\
\hline & Raw chicken & 1 & & \\
\hline \multirow{2}{*}{ Salmonella Mbandaka } & Raw fish & 1 & 2 & \multirow{2}{*}{5.6} \\
\hline & Uncooked chicken file & 1 & & \\
\hline \multirow{2}{*}{ Salmonella Muenchen } & Fresh sausage & 1 & 2 & \multirow{2}{*}{5.6} \\
\hline & Uncooked seasoned chicken & 1 & & \\
\hline Salmonella Newport & Cheese curd & 2 & 2 & 5.6 \\
\hline
\end{tabular}


Salmonella Schwarzengrund

Salmonella Typhimurium

Salmonella Agona

Salmonella Cubana

Salmonella enterica subsp. enterica $(0: 6,7)$

Salmonella enterica subsp. enterica (O:6,7:e,h:-)

Salmonella enterica subsp. enterica (O:6,7:r:-)

Salmonella enterica subsp. enterica $(\mathrm{O}: 6,8)$

Salmonella enterica subsp. enterica $(\mathrm{O}: 11)$

Salmonella Heidelbeg

Salmonella Kentucky

Salmonella Livingstone

Salmonella Muenster

Salmonella Orion

\section{TABLE I (continuation)}

$$
\text { Raw salad }
$$

Raw chicken

Raw salad

Raw beef

Raw chicken

Raw chicken

Raw salad

Cheese curd

Cheese curd

Uncooked ground beef

Cooked salad

Cheese curd

Raw salad

Smoked meat

Halfbeak fish

Sausage
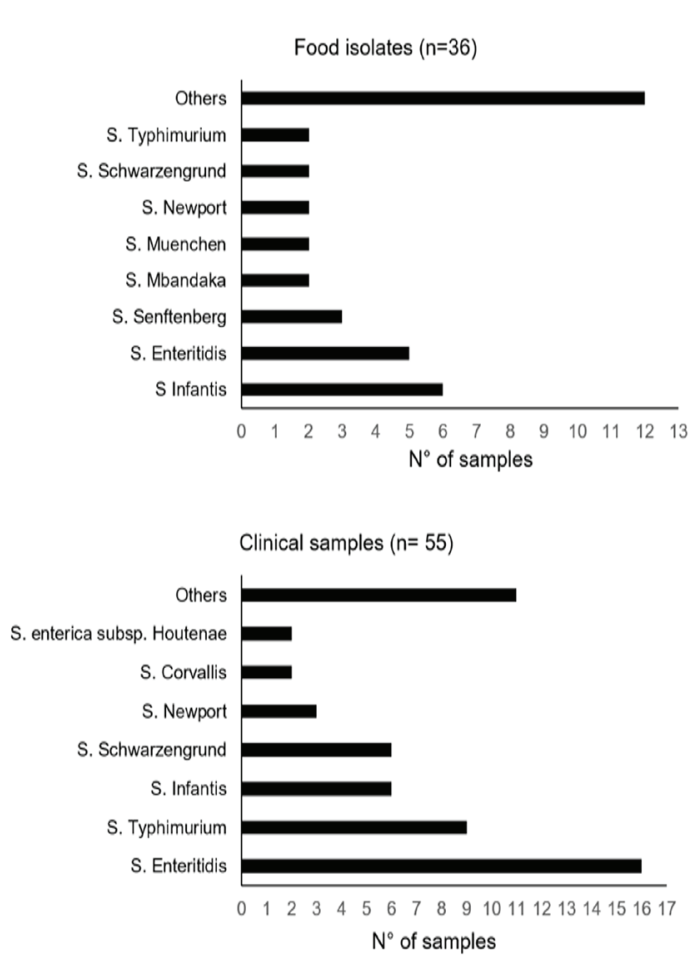

Figure 1 - Distribution of Salmonella serotypes in food and clinical samples. low resistance rates. All isolates were susceptible to ciprofloxacin and levofloxacin.

Among resistant isolates, this study identified 15 patterns among resistant isolates, four of which were found only in isolates from foods (GEN, NLX/TET, NLX/TMS and AMP/TET/TMS). Nine patterns were identified only in clinical isolates (NLX, TET, NLX/TET, TET/TMS, AMP/NLX/ TET, AMP/TET/TMS, AMP/NLX/TMS, AMP/ AMC/CLO/TET and AMP/GEN/NLX/TET), and two patterns were common to both groups (NLX and AMP/CFL/CRO/CTX/TET/TMS/NLX). The most frequently observed pattern was NLX identified among Salmonella Enteritidis isolates from food (16.0\%) and clinical samples (11.0\%). Overall, antibiotic resistance between clinical and food isolates showed that clinical isolates are more resistant to antibiotics (Figure 2). The Salmonella Schwarzengrund showed multidrug resistance with resistance to phenotype $\mathrm{AMP} / \mathrm{CFL} / \mathrm{CRO} / \mathrm{CTX} /$ 
TABLE II

Distribution of serotypes of Salmonella spp. isolated from clinical samples $(\mathrm{N}=\mathbf{5 5})$.

\begin{tabular}{|c|c|c|c|c|}
\hline Serotypes & Sample Source & $\mathbf{N}^{0}$ of Isolates & Total & $\%$ \\
\hline \multirow{2}{*}{ Salmonella Enteritidis } & Stool & 11 & \multirow{2}{*}{16} & \multirow{2}{*}{29.1} \\
\hline & $\mathrm{CSF}$ & 5 & & \\
\hline \multirow{2}{*}{ Salmonella Typhimurium } & Stool & 6 & \multirow{2}{*}{9} & \multirow{2}{*}{16.4} \\
\hline & $\mathrm{CSF}$ & 3 & & \\
\hline Salmonella Infantis & Stool & 6 & 6 & 10.9 \\
\hline Salmonella Schwarzengrund & Stool & 6 & 6 & 10.9 \\
\hline Salmonella Newport & Stool & 3 & 3 & 5.5 \\
\hline Salmonella Corvallis & Stool & 2 & 2 & 3.7 \\
\hline \multirow{2}{*}{ Salmonella enterica subsp. Houtenae } & Blood & 1 & \multirow{2}{*}{2} & \multirow{2}{*}{3.7} \\
\hline & $\mathrm{CSF}$ & 1 & & \\
\hline Salmonella Agona & Stool & 1 & 1 & 1.8 \\
\hline Salmonella Anatum & Blood & 1 & 1 & 1.8 \\
\hline Salmonella Cerro & Stool & 1 & 1 & 1.8 \\
\hline Salmonella Derby & Stool & 1 & 1 & 1.8 \\
\hline Salmonella enterica subsp. enterica (O:6,7:e,h:-) & Stool & 1 & 1 & 1.8 \\
\hline Salmonella enterica subsp. enterica $(\mathrm{O}: 4,5:-: 1,6)$ & Stool & 1 & 1 & 1.8 \\
\hline Salmonella Indiana & Stool & 1 & 1 & 1.8 \\
\hline Salmonella Mbandaka & Stool & 1 & 1 & 1.8 \\
\hline Salmonella Montevideo & Stool & 1 & 1 & 1.8 \\
\hline Salmonella Panama & Stool & 1 & 1 & 1.8 \\
\hline Salmonella Worthington & $\mathrm{CSF}$ & 1 & 1 & 1.8 \\
\hline
\end{tabular}

CSF (Cerebrospinal Fluid)

TET/TMS/NLX found in both the food (3.0\%) and clinical isolates $(9.0 \%)$.

The study identified 47 PFGE types, including 11 clonal groups, ranging from 2 to 20 isolates. The isolates were grouped in two major clusters designated as PFGE A (20 isolates) and PFGE B (11 isolates). In the PFGE A cluster, 19 isolates of Salmonella Enteritidis and one Salmonella Infantis exhibited similarity above $90.0 \%$ (Figure 3 ).

The PFGE A cluster included isolates from food (4), feces (11) and CSF (5) identified from 1996 to 2011 in different localities of the Bahia State. The PFGE B cluster contained 11 isolates of Salmonella Infantis (food [7] and feces [4]) (Figure $4 b)$. The PFGE C cluster contained seven isolates of Salmonella Schwarzengrund (food [1] and feces [6]) (Figure 4c). In total, 85.7\% of food samples were of animal origin and identified over a threeyear period (2009-2011).

\section{DISCUSSION}

Salmonella is an environmentally persistent pathogen that that survives and multiplies in diverse environments, and is one of the most common bacteria in food-borne diseases in humans. The CDC estimated that, each year, there are approximately one million cases of salmonellosis caused by non-typhoidal Salmonella (CDC 2011). In Brazil, salmonellosis has been substantially underestimated, thus, this study brings important 
TABLE III

Antimicrobial resistance profiles for Salmonella isolates from food and clinical samples.

\begin{tabular}{|c|c|c|}
\hline $\begin{array}{l}\text { Resistance } \\
\text { profile }\end{array}$ & $\begin{array}{c}\mathrm{N}^{\mathrm{o}} \text { of strain isolated } \\
\text { from foods } \\
(\mathrm{n}=12 / 36)\end{array}$ & $\begin{array}{l}\mathrm{N}^{\mathrm{o}} \text { of strain } \\
\text { isolated from } \\
\text { clinical samples } \\
(\mathrm{n}=22 / 55)\end{array}$ \\
\hline GEN & 2 & \\
\hline NLX & 6 & 6 \\
\hline NLX* & & 1 \\
\hline TET & & 1 \\
\hline NLX/TET & 1 & \\
\hline NLX*/TET & & 1 \\
\hline NLX/TMS & 1 & \\
\hline TET/TMS & & 1 \\
\hline $\begin{array}{l}\text { AMP/NLX/ } \\
\text { TET }\end{array}$ & & 1 \\
\hline $\begin{array}{l}\text { AMP/TET/ } \\
\text { TMS }\end{array}$ & 1 & \\
\hline $\begin{array}{l}\text { AMP*/NLX/ } \\
\text { TMS }\end{array}$ & & 1 \\
\hline $\begin{array}{l}\text { AMP*/TET/ } \\
\text { TMS }\end{array}$ & & 1 \\
\hline $\begin{array}{l}\text { AMP/AMC*/ } \\
\text { CLO/TET }\end{array}$ & & 1 \\
\hline $\begin{array}{l}\text { AMP/GEN/ } \\
\text { NLX/TET }\end{array}$ & & 3 \\
\hline $\begin{array}{l}\mathrm{AMP} / \mathrm{CFL} / \\
\mathrm{CRO} / \mathrm{CTX} / \\
\mathrm{TET} / \mathrm{TMS} / \\
\text { NLX* }^{*}\end{array}$ & 1 & 5 \\
\hline
\end{tabular}

GEN (gentamicin); NLX (nalidixic acid); TET (tetracycline); TMS (trimethoprim/sulfamethoxazole); AMP (ampicillin); AMC (amoxicillin/clavulanate); CLO (chloramphenicol); CFL (cephalothin); CRO (ceftriaxone); CTX (cefotaxime); *Intermediate sensitivity.

contribution to public health in Brazil and all over the world.

The most frequently observed serotypes in food samples are similar to those reported in other regions of Brazil and around the world (Murakami et al. 2007, EFSA 2011, Pulido-Landinez et al. 2013). Of 16 serotypes identified among food isolates, Salmonella Infantis was the most frequent serovar (16.0\%), followed by Salmonella Enteritidis $(14.0 \%)$. In regards to clinical samples, the

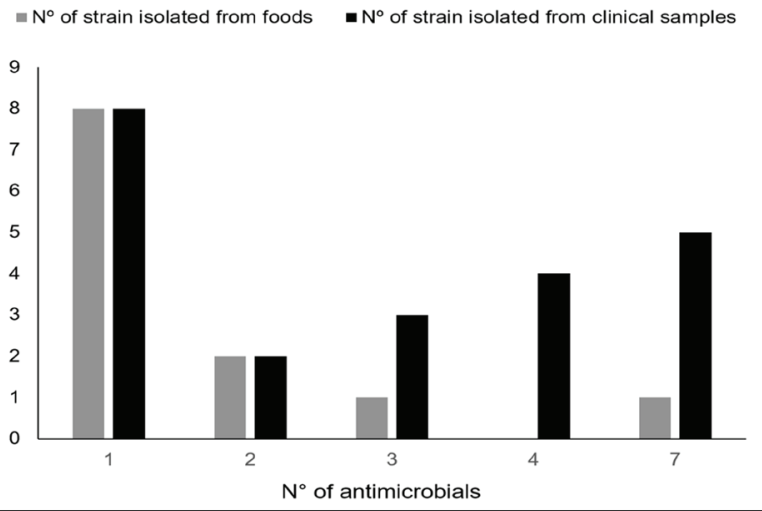

Figure 2 - Resistance of Salmonella serotypes in food and clinical samples to a variety of antimicrobials. X-axis represents the number of antimicrobials to which strains are resistant. Isolates from human and food were grouped according to the number of antimicrobial agents they were resistant.

predominant was Salmonella Enteritidis (29.0\%), followed by Salmonella Typhimurium (16.0\%), Salmonella Infantis (11.0\%) and Salmonella Schwarzengrund (11.0\%).

Derived food products such as poultry meat and eggs are the main forms of infection by Salmonella spp. in humans (Gantois et al. 2009). A large number of serovars of Salmonella are pathogenic for humans, so the ability to genus Salmonella to cause a disease depends on several virulence determinant factors. Therefore, there is a less diverse serotypes among clinical isolates than food samples. Higher frequencies of Salmonella Enteritidis and Salmonella Typhimurium were also found in other studies in Brazil and elsewhere, and they pose a threat to human health (Silva and Duarte 2002, Mürmann et al. 2009).

Salmonella Enteritidis was the most common serotype in the country. In 1993, Salmonella Enteritidis accounted for approximately 10.0\% of the Salmonella serotypes isolated from human samples, and from then on it became the dominant serotype in both human and non-human samples (Taunay et al. 1996). In 1994 and 1995, it accounted for $43 \%$ and $65 \%$ of Salmonella Enteritidis isolated from humans, respectively, in Sao Paulo 


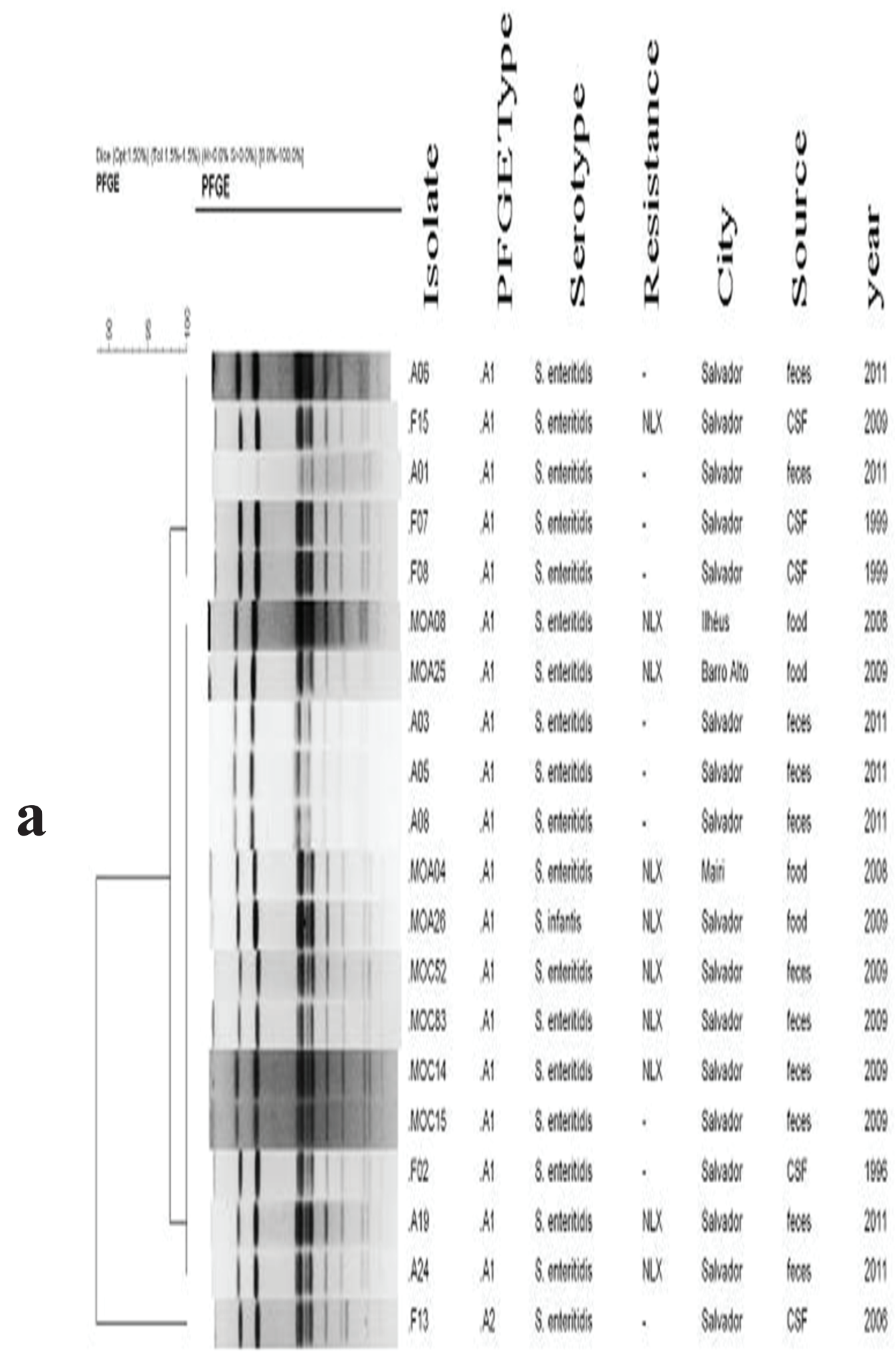

Figure 3 - Dendrogram representing genetic relationships among Salmonella Enteritidis (a) strains based on PFGE. The data were sorted by the UPGMA method. NLX (nalidixic acid). 

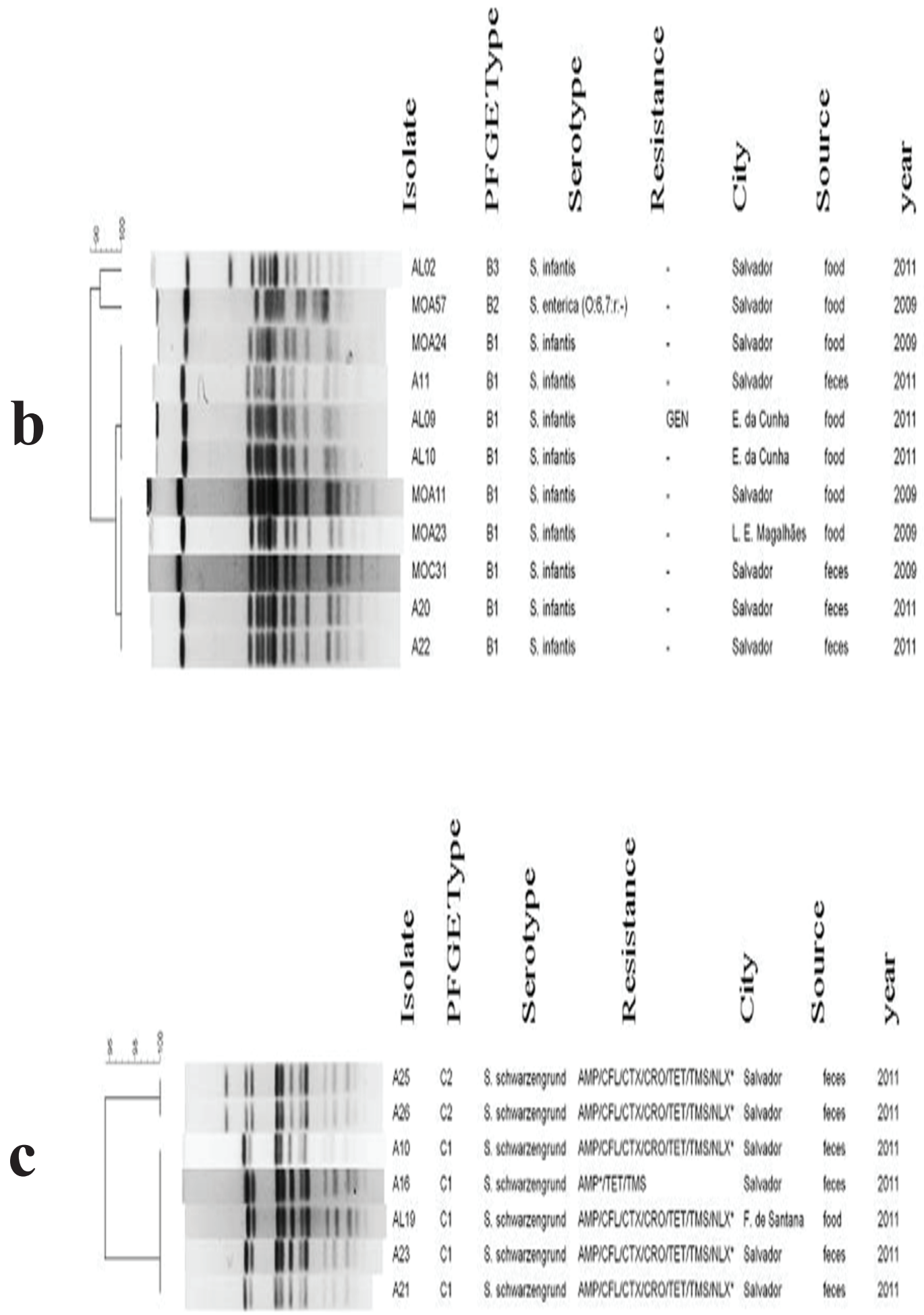

Figure 4 - Dendrogram representing genetic relationships among Salmonella Infantis (b) and Salmonella Schwarzengrund (c) strains based on PFGE. The data were sorted by the UPGMA method. GEN (gentamicin); NLX (nalidixic acid); TET (tetracycline); TMS (trimethoprim/sulfamethoxazole); AMP (ampicillin); CFL (cephalothin); CRO (ceftriaxone); CTX (cefotaxime). 
(Taunay et al. 1996). Modifications in serotype distribution reflect changes in animal production and the spreading of new serotypes due to world trade. Of a particular concern is the emergence of resistance to multiple antimicrobials. Resistance to quinolones, such as nalidixic acid, has become a significant problem for public health and has been increasing in recent years, mainly due to the liberal use of quinolone drugs in aquaculture and industrial animal production (Oliveira et al. 2005). In contrast, antibiotics such as aminoglycosides, florfenicol and nalidixic acid, not commonly used in animal health and production showed no resistance (Piras et al. 2011, Li et al. 2014).

Antimicrobial resistance to at least one antibiotic was identified in $40.0 \%$ and $33.0 \%$ of clinical and food isolates, respectively. In the Southern Brazil, $82.0 \%$ of Salmonella samples of fresh pork sausage were resistant to at least one antibiotic tested (Mürmann et al. 2009). In the US, $47.0 \%$ of Salmonella Heidelberg isolates from human patients were resistant to antimicrobials (Han et al. 2011). Salmonella multidrug resistance is a growing concern since it limits treatment options for invasive disease, and it could lead to the transfer of resistance to other pathogenic organisms. In this study, a relative high frequency of multidrug-resistant Salmonella (25.0\% of clinical isolates and $11.0 \%$ of food isolates) represents an additional public health risk, and Salmonella Schwarzengrund, in special, seemed to be resistant to six or more antibiotics.

The current gold standard method used to evaluate relatedness among Salmonella strains is PFGE has been established as important for the discrimination, characterization, and investigation of food-borne outbreaks (CDC 2010). Thus, PFGE fingerprinting shows several foods isolates that clustered with clinical isolates, mainly Salmonella Enteritidis and Salmonella Infantis among cities more than 500 miles apart, with persistence and geographical transmission in the
Bahia State. However, other studies have described the limited discriminatory power of PFGE for Salmonella Enteritidis (CDC 2010, Mezal et al. 2014). A combination of different typing methods may be better to achieve best resolution for the discrimination of highly clonal organisms.

The combined use of different patterns of resistance and genotypes to analyze pathogenic isolates from food has been a useful way to identify the origins of outbreaks, establish sources of contamination, determine the etiological agents responsible for outbreaks, understand the epidemiology of food-borne disease and facilitate further studies on the spread of antibiotic-resistant isolates. This study provides data that indicate a probable transmission of Salmonella from food sources to cause infections in humans, establishing a serious risk to public health.

In this study, the most prevalent serotype in food samples was Salmonella Infantis and clinical samples of Salmonella Enteritidis. The most frequently observed resistance profiles were the NLX (nalidixic acid) and multi-resistance AMP / CFL / CRO / CTX / TET / TMS / NLX* (ampicillin, cephalothin, ceftriaxone, cefotaxime, tetracycline and trimethoprim / sulfametazol, nalidixic acid), common to isolates from food and clinical samples. In addition, clonal groups, found among strains epidemiologically unrelated, suggested that some isolated persisted in the environment over the years in different cities of Bahia. Thus, our results indicate that the clonal groups were both causing diseases and food contamination, emphasizing the need to maintain a system of surveillance for foodborne disease.

\section{ACKNOWLEDGMENTS}

The authors would like to thank to Dalia dos Prazeres, Laboratório de Enterobactérias da Fundação Oswaldo Cruz, Rio de Janeiro, Brazil for serotyping the Salmonella isolates. 


\section{REFERENCES}

ABBASSI-GHOZZI I, JAOUANI A, HAMMAMI S, MARTINEZ-URTAZA J, BOUDABOUS A AND GTARI M. 2012. Molecular analysis and antimicrobial resistance of Salmonella isolates recovered from raw meat marketed in the area of "Grand Tunis", Tunisia. Pathol Biol 60(5): e49-e54.

BRAZILIAN MINISTRY OF HEALTH. 2009. Secretary of Surveillance of Health [Internet]. Available from: http:// www.saude.gov.br.

CAMPIONI F, MORATTO BERGAMINI AM AND FALCÃO JP. 2012. Genetic diversity, virulence genes and antimicrobial resistance of Salmonella Enteritidis isolated from food and humans over a 24-year period in Brazil. Food Microbiol 32(2): 254-264.

CDC - CENTER FOR DISEASE CONTROL AND PREVENTION. 2010. PulseNet. Available from: http:// www.cdc.gov/pulsenet/.

CDC - CENTER FOR DISEASE CONTROL AND PREVENTION. 2011. Estimates of Foodborne Illness. Available from: http://www.cdc.gov/ foodborneburden/2011-foodborne-estimates.html.

CHU C, WONG DW, WANG MH, LIN HH, CHEN YS, TIEN N, SHIH MC, CHEN TH AND CHIU CH. 2009. Genotyping, plasmid analysis, and antimicrobial susceptibility of Salmonella enterica serotype Enteritidis isolates from humans and chickens in central Taiwan. J Formos Med Assoc 108(10): 765-771.

CLSI - CLINICAL AND LABORATORY STANDARD INSTITUTE. 2016. Performance Standards for Antimicrobial Susceptibility Testing, $26^{\text {th }}$ ed., Informational Supplement. CLSI document M100-S26. Wayne, Pennsylvania: Clinical and Laboratory Standards Institute.

EUROPEANFOOD SAFETYAUTHORITYAND EUROPEAN CENTRE FOR DISEASE PREVENTION AND CONTROL. 2011. The European Union Summary Report on Trends and Sources of Zoonosis, Zoonotic Agents and Food-borne Outbreaks in 2009. EFSA 9(3): 01-378.

GANTOIS I, DUCATELLE R, PASMANS F, HAESEBROUK F, GAST R, HUMPHREY TJ AND VAN IMMERSEEL F. 2009. Mechanisms of egg contamination by Salmonella Enteritidis. FEMS Microbiol Rev, Amsterdam 33(4): 718-738.

HAN J, DAVID DE, DECK J, LYNNE AM, KALDHONE P, NAYAK R, STEFANOVA R AND FOLEY SL. 2011. Comparison of Salmonella enterica serovar Heidelberg isolates from human patients with those from animal and food sources. J Clin Microbiol 49(3): 1130-1133.

LI P, WU D, LIU K, SUOLANG S, HE T, LIU X, WU C, WANG Y AND LIN D. 2014. Investigation of antimicrobial resistance in Escherichia coli and enterococci isolated from Tibetan pigs. PLoS ONE 9(4): e95623.
LU Y ET AL. 2011. Prevalence of antimicrobial resistance among Salmonella isolates from chicken in China. Foodborne Pathog Dis 8(1): 45-53.

MEZAL EH, SABOL A, KHAN MA, ALI N, STEFANOVA R AND KHAN AA. 2014. Isolation and molecular characterization of Salmonella enterica serovar Enteritidis from poultry house and clinical samples during 2010. Food Microbiol 38: 67-74.

MURAKAMI K, TSHIHARA T, HORIKAWA K AND ODA T. 2007. Features of Salmonella serovars among food handlers in Kyushu, Japan. New Microbiol 30(2): 155159.

MÜRMANN L, SANTOS MC AND CARDOSO M. 2009. Prevalence, genetic characterization and antimicrobial resistance of Salmonella isolated from fresh pork sausages in Porto Alegre, Brazil. Food Control 20: 191-195.

OLIVEIRA SD, FLORES FS, SANTOS LR AND BRANDELLI A. 2005. Antimicrobial resistance in Salmonella Enteritidis strains isolated from broiler carcasses, food, human and poultry-related samples. Int J Food Microbiol 97(3): 297-305.

PIRAS F, BROWN DJ, MELONI D, MUREDDU A AND MAZZETTE R. 2011. Investigation of Salmonella enterica in Sardinian slaughter pigs: prevalence, serotype and genotype characterization. Int J Food Microbiol 151(2): 201-209.

PULIDO-LANDINEZ M, SANCHEZ-INGUNZA R, GUARD J AND DO NASCIMENTO VP. 2013. Assignment of serotype to Salmonella enterica isolates obtained from poultry and their environment in southern Brazil. Lett Appl Microbiol 57(4): 288-294.

SILVA EM AND DUARTE A. 2002. Salmonella Enteritidis em aves: retrospectiva no Brasil. R Bras Ci Solo 4(2): 85100.

SOUZA CO, RAMOS FLP, MOTA CM, SANTOS LVC AND LOPES ML. 2010. Resistencia antimicrobiana de Salmonella Typhi identificadas en el Estado de Pará, Brasil. Rev Pan-Amaz Saude 1(2): 61-65.

TAUNAY AE, FERNANDES SA, TAVECHIO AT, NEVES BC, DIAS AMG AND IRINO K. 1996. The role of public health laboratory in the problem of salmonellosis in Sao Paulo, Brazil. Rev Inst Med Trop Sao Paulo 38(2): 119127.

WANG H, YE K, WEI X, CAO J, XU X AND ZHOU G. 2013. Occurrence, antimicrobial resistance and biofilm formation of Salmonella isolates from a chicken slaughter plant in China. Food Control 33(2): 378-384.

WEINBERGER M AND KELLER N. 2005. Recent trends in the epidemiology of non-typhoid Salmonella and antimicrobial resistance: the Israeli experience and worldwide review. Curr Opin Infect Dis 18(6): 513-521.

YANG B ET AL. 2013. Serotyping, antimicrobial susceptibility, pulse field gel electrophoresis analysis of 
Salmonella isolates from retail foods in Henan Province, China. Food Control 32(1): 228-235.

ZHAO S, WHITE DG, FRIEDMAN SL, GLENN A, BLICKENSTAFF $\mathrm{K}$, AYERS SL, ABBOTT JW,
HALL-ROBINSON E AND MC-DERMOTT PF. 2008. Antimicrobial resistance in Salmonella enterica serovar Heidelberg isolates from retail meats, including poultry, from 2002 to 2006. Appl Environ Microbiol 74(21): 6656-6662. 